\title{
RESEARCH
}

\section{Construction of a 750-kb Bacterial Clone Contig and Restriction Map in the Region of Human Chromosome 21 Containing the Progressive Myoclonus Epilepsy Gene}

\author{
Nancy E. Stone, ${ }^{1}$ Jian-Bing Fan, ${ }^{1,2}$ Virginia Willour, ${ }^{1}$ \\ Len A. Pennacchio, ${ }^{1,3}$ Janet A. Warrington, ${ }^{1}$ An $\mathrm{Hu}^{1}{ }^{1}$ \\ Albert de la Chapelle, ${ }^{4}$ Anna-Elina Lehesjoki, ${ }^{4}$ David R. Cox, ${ }^{1,2}$ and \\ Richard M. Myers ${ }^{1,2,5}$
}

\footnotetext{
'Department of Genetics, Stanford University School of Medicine, Stanford, California 94305-5120; ${ }^{2}$ Stanford Human Genome Center, Stanford University School of Medicine, Palo Alto, California 94304; ${ }^{3}$ Department of Biology, Stanford University, Stanford, California 94305; ${ }^{4}$ Department of Medical Genetics, University of Helsinki, 00290 Helsinki, Finland
}

The gene responsible for progressive myoclonus epilepsy of the Unverricht-Lundborg type (EPMI) is located on human chromosome 2lq22.3 in a region defined by recombination breakpoints and linkage disequilibrium. As part of an effort to clone the EPMl gene on the basis of its chromosomal location, we have constructed a 753-kb bacterial clone contig that encompasses the region containing the gene. Because DNA markers from the region did not identify intact yeast artificial chromosome (YAC) clones after screening several libraries, we built the contig from cosmid clones and used bacterial artificial chromosome (BAC) and bacteriophage $\mathrm{Pl}$ clones to fill gaps. In addition to constructing the clone contig, we determined the locations of the EcoRI, Sacll, Eagl, and Notl restriction sites in the clones, resulting in a high-resolution restriction map of the region. Most of the contig is represented by a level of redundancy that allows the orders of most restriction sites to be determined, provides multiple data points supporting the clone orders and orientations, and allows a set of clones with a minimum degree of overlap to be chosen for efficient additional analysis. The clone and restriction maps are in excellent agreement with maps generated of the region by other methods. These ordered bacterial clones and the mapping information obtained from them provide valuable reagents for isolating candidate genes for EPMl, as well as for determining the nucleotide sequence of a 750 $\mathrm{kb}$ region of the human genome.

Progressive myoclonus epilepsy of the Unverricht-Lundborg type (EPM1) is inherited as an autosomal recessive disorder and is characterized by severe stimulus-sensitive myoclonus, tonicclonic seizures, and progressive neural degeneration. The age of onset is typically between 6 and 15 years. This condition is one of a group of five different subtypes of progressive myoclonus epilepsy, all of which show progressive neurodegeneration and variable degrees of severity. Unlike the other progressive myoclonus epilepsies, EPM1 is not characterized by biochemical mark-

${ }^{5}$ Corresponding author.

E-MAIL myers@shgc.stanford.edu; FAX (415) 725-9689. ers such as inclusion bodies or storage material, and diagnosis of the disease is usually based on careful evaluation of the clinical history, typical electroencephalograph abnormalities, and the exclusion of the other four subtypes (Lafora's disease, MERRF syndrome, neuronal ceroid lipofuscinosis, and sialidosis). Identification of the mutated gene responsible for EPM1 will likely contribute to our understanding of the pathophysiology of the disease, give insights into the genesis of seizures in other epilepsies, broaden our knowledge of normal brain function, and aid in the discovery of more effective therapies for different forms of epilepsy.

The locus for EPM1 was assigned to chromo- 


\section{CLONE CONTIG OF THE HUMAN EPMI REGION OF $21,22.3$}

some $21 \mathrm{q} 22.3$ by linkage in Finnish families to the polymorphic DNA markers BCEI, D21S154, and D21S112 (Lehesjoki et al. 1991), and its location was refined by further linkage analysis to a 3.5 million base pair $(\mathrm{Mb})$ region defined by the markers MX1 and CD18 (Lehesjoki et al. 1992), with a maximum multipoint lod score of 11.04 at loci D21S154-PFKL. Analysis of an American family with EPM1 defined crossover events that refined the proximal marker to be CBS, shrinking the size of the region containing the gene to approximately $2 \mathrm{Mb}$ (Lehesjoki et al. 1993a). As a result of pronounced founder effects and bottlenecks in the Finnish population history, coupled with population expansion in isolation (de la Chapelle 1993), it can be assumed that most cases of EPM1 arose from a single founder mutation. Results from linkage disequilibrium analysis of 38 Finnish families support this hypothesis and suggest that the EPM1 gene lies within $0.3 \mathrm{cM}$ from the markers D21S25, PFKL, and D21S154 (Lehesjoki et al. 1993b).

Our laboratories are using positional cloning methods to identify the gene responsible for EPM1. Toward this goal, we constructed a bacterial clone contig of $753 \mathrm{~kb}$ in the region of chromosome 21 that likely contains the gene. We also determined a high-resolution EcoRI restriction enzyme map and the positions of three rare cutter enzyme sites across the entire cloned region.

\section{RESULTS}

\section{Strategy}

Our laboratories (Zuo et al. 1993; Patil et al. 1994) and others (e.g., see Baxendale et al. 1993; Xie et al. 1993; Murrell et al. 1995) have generated cosmid contigs of several hundred kilobase stretches in a few regions of the human genome by using yeast artificial chromosome (YAC) clones to isolate cosmid clones. However, because we were unable to identify YAC clones in most of the segment of chromosome 21 containing the EPM1 gene, we used an alternative strategy to build a bacterial clone contig of the region. We initially used the available DNA markers from the region as hybridization probes against a chromosome 21-specific cosmid library to isolate cosmids from which to begin building our contig. Cosmids were evaluated by restriction digest with ethidium staining, and those sharing two or more bands of identical size were considered to be overlapping and were arranged into small con- tig groups. Single cosmid fragments and, in some cases, entire cosmids, were used as hybridization probes to confirm overlaps. Restriction fragments from the ends or near the ends of cosmids were used as hybridization probes in pulsed-field gel electrophoresis (PFGE) mapping experiments to ensure that the cosmids were derived from the appropriate NotI restriction fragment, as defined by the map of Ohki and colleagues (Ichikawa et al. 1993). Once confirmation was obtained, these probes were then used to screen the cosmid library to extend the contig. In two regions where we failed to isolate cosmids that would fill in gaps, we obtained DNA sequence information from the cosmids at the ends of each contig, designed sequence-tagged sites (STSs), and screened P1 and bacterial artificial chromosome (BAC) libraries by PCR to obtain clones that completed the contig. The locations of EcoRI and several rare-cutter restriction sites were determined by restriction analysis of the entire set of clones.

\section{The Map}

These efforts led to the construction of a $753-\mathrm{kb}$ contig with continuous bacterial clone coverage, most of which is represented by multiple overlapping clones (Fig. 1). A total of 108 cosmids, three P1, and two BAC clones comprise the contig. The map contains 14 STSs and a single published hybridization probe, resulting in a map with markers separated by an average distance of $50 \mathrm{~kb}$. Of these, six are new markers that we developed in this study (D21S1988, D21S1953, 2489/90, D21S1978, 2493/4, and D21S1991). Five of the markers described previously are NotI linking clones described by Ichikawa et al. (1993; D21S1458/LJ112, D21S1459/LB2T, D21S1460/ LJ104, D21S1461/LB85S, and D21S400/LL23SP). Two are described anonymous DNA segments, D21S25 and D21S154, one is the gene PFKL, and one is a CA repeat (D21S1259).

In addition to restriction mapping some cosmids during the construction of the contig, we determined the sizes of the EcoRI fragments in all the cosmids, BACs, and P1 clones by digesting them with the enzyme and electrophoresing the digests on long agarose gels. Cosmids known to be overlapping from the screening experiments were loaded on the gels adjacent to one another to simplify the comparisons of the digest patterns. The depth of the contig in clones was great enough that a large fraction of the EcoRI fragments were interrupted by at least one cosmid, 
STONE ET AL.

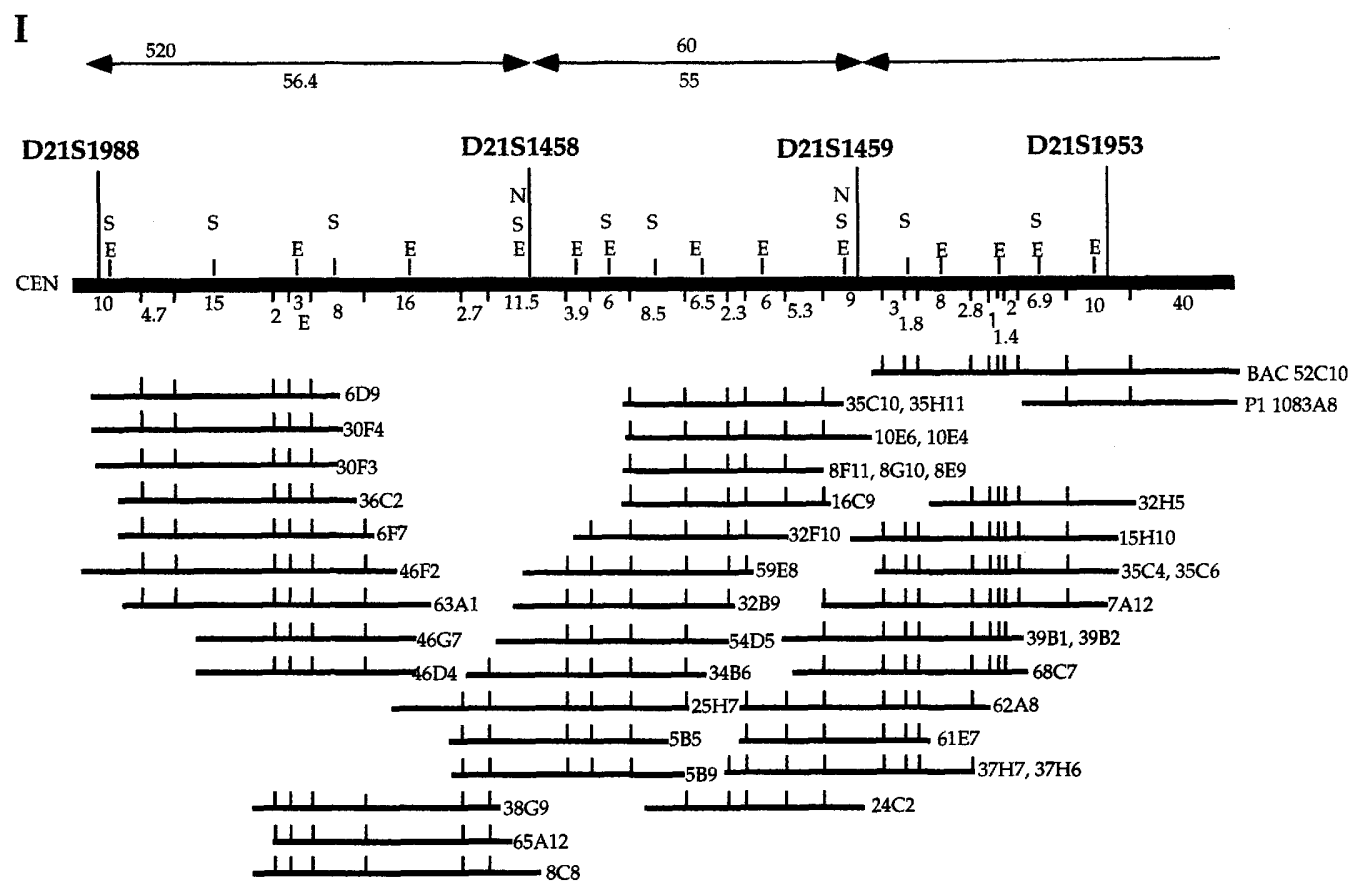

II

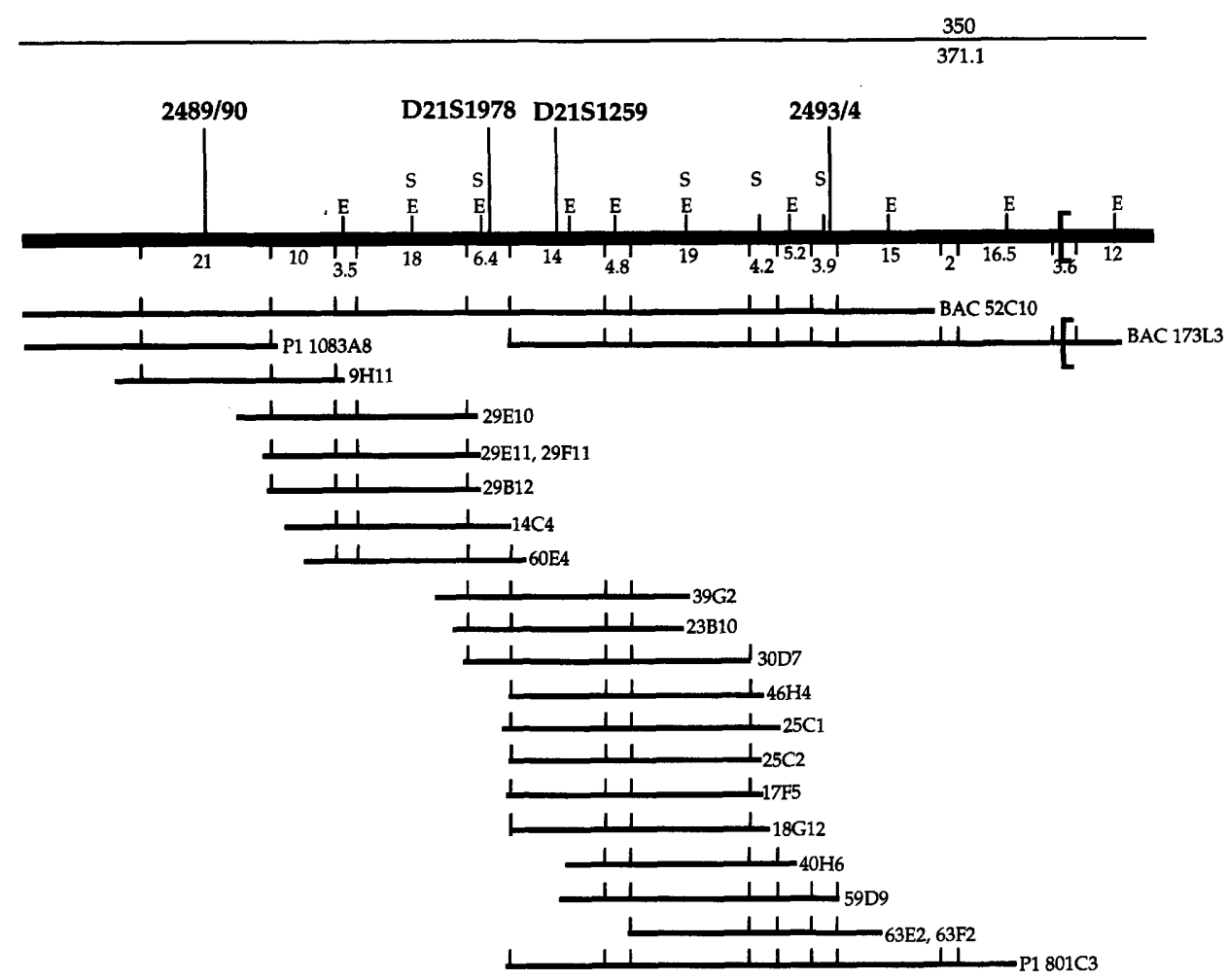

Figure 1 A 753-kb bacterial clone contig of the EPM1 gene region and a portion of the autoimmune polyglandular disease type I gene region on human chromosome 21q22.3. The map extends in the centromeric to telomeric direction from left to right and is drawn in four contiguous segments labeled I-IV. The top horizontal arrows in each segment designate the Notl fragments identified in the map of Ichikawa et al. (1993); the numbers above and below these lines indicate the sizes of the fragments (in kb) determined from their map and our map, respectively. DNA markers are designated by bold letters and numbers, and Sadl, Eagl, and Notl sites are designated by the letters $S, E$, and N, respectively, above the thick black horizontal line. The EcoRI fragments are demarcated by tick marks below the thick line, and their sizes in kb are shown between each pair of tick marks. 
III

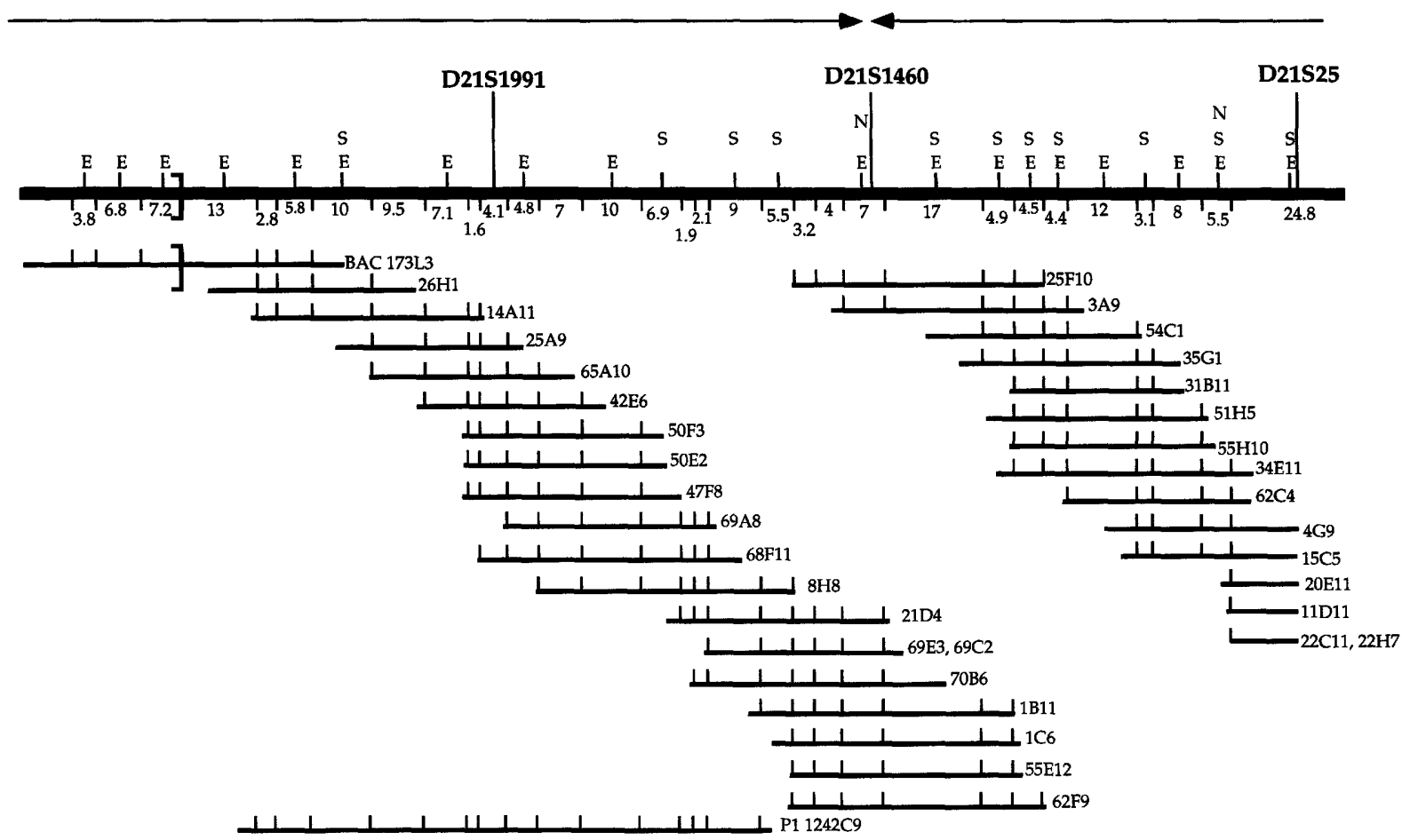

IV

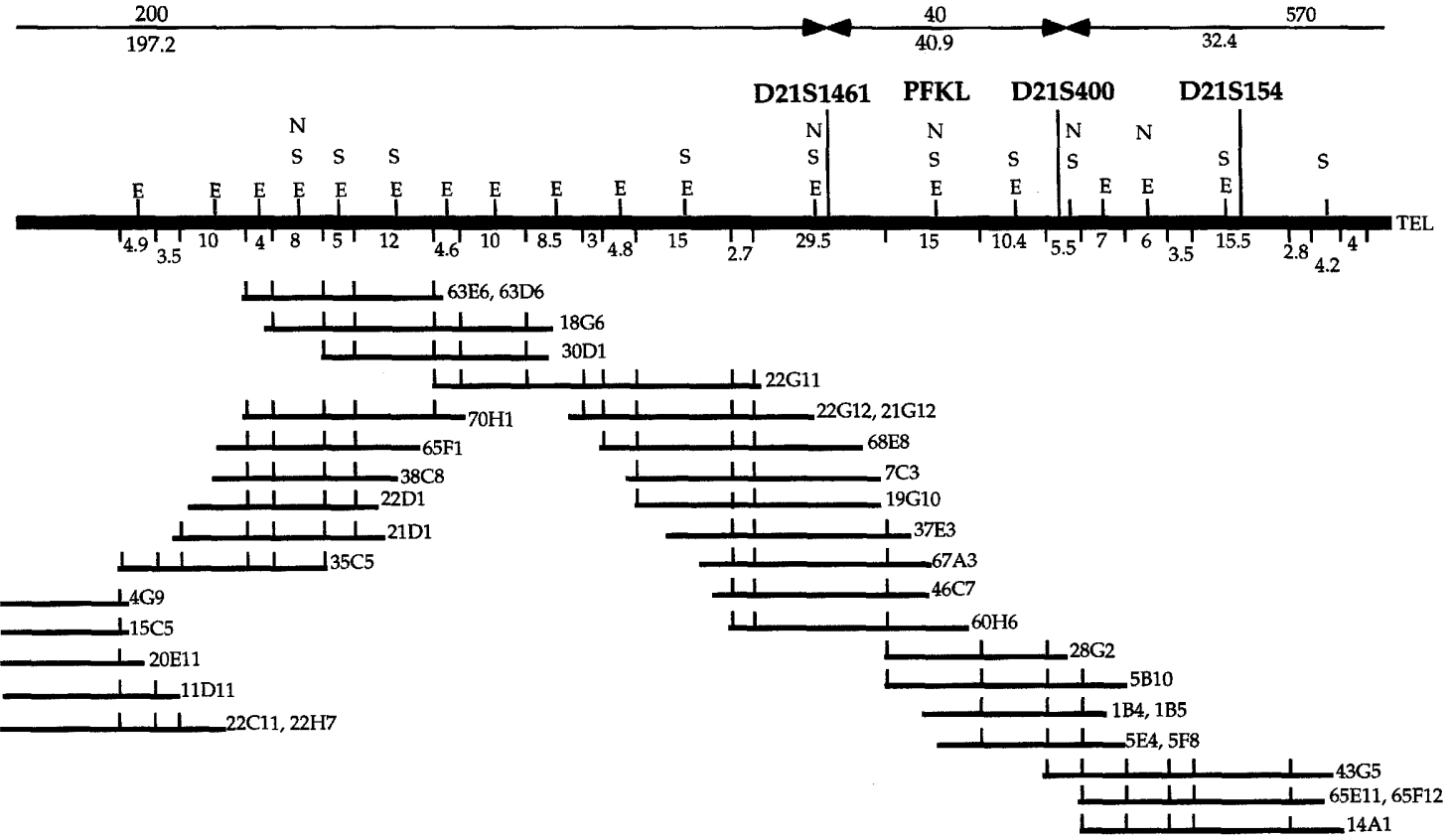

Cosmids, BACs, and P1s are shown as horizontal lines with their EcoRI sites designated with tick marks and their microtiter well positions from their original library addresses to the right of each line. The cases of cosmid clones that have two well position names are likely duplicates of the same clone. All clones with names beginning with a number are cosmid clones, whereas the BAC clone names begin with the letters BAC followed by a well position number, and the $\mathrm{P} 1$ clone names begin with the designation $\mathrm{P} 1$ followed by a well position number. The orders of the EcoRI fragments in the segment of BAC 173L3 that are present in the contig as single clone coverage were not determined and are contained within the brackets. 


\section{STONE ET AL.}

BAC or P1 end, which allowed the orders of almost all the fragments to be determined. The portion of BAC 173L3 that contains only single coverage contains several EcoRI sites whose orders were not determined. This EcoRI map provided a framework for identifying the locations of all the rare-cutter sites for NotI, EagI, and SacII in the region. Double digests were performed on an overlapping set of cosmids with EcoRI and each of the rare-cutter enzymes, and compared to a digest with EcoRI alone. In total, we identified 9 NotI, 59 EagI, and 35 SacII sites in the 753-kb region.

We determined the total length of the contig to be $\sim 753 \mathrm{~kb}$ by adding the sizes of the EcoRI fragments. Because the depth of clones was $\sim 10$ fold, we were able to use only the internal EcoRI fragments of each clone insert to determine distance. This allowed a more accurate estimate of length of the contig to be made than would have been possible if the end fragments of the clones had been used in the calculations. We also calculated lengths for the distances between each of the NotI linking clones by adding the sizes of EcoRI fragments, allowing a comparison with the NotI fragment sizes obtained in the published NotI map estimated by PFGE (Ichikawa et al. 1993). The fragment sizes correlated well (Fig. 1, numbers above and below arrows at the top of each map segment). Ichikawa et al. (1993) estimated that linking clone markers D21S1458 and D21S1459 flanked a 60-kb NotI fragment, and we calculated the fragment to be $\sim 55 \mathrm{~kb}$. The next distal fragment, flanked by the markers D21S1459 and D21S1460, was reported as $350 \mathrm{~kb}$ from the pulsed-field map and compares with $370 \mathrm{~kb}$ from the cosmids. The final two fragments, between linking clones D21S1460 and D21S1461 and clones D21S1461 and D21S400, compare at $200 \mathrm{~kb}$ versus $197 \mathrm{~kb}$ and $40 \mathrm{~kb}$ versus $41 \mathrm{~kb}$ by the two methods, respectively.

\section{DISCUSSION}

We used bacterial clones to obtain a highresolution clone and restriction map of the region of chromosome $21 \mathrm{q}$ that likely contains the gene responsible for EPM1. The argument for the disease gene lying in this contig is based on a combination of standard genetic mapping and linkage disequilibrium data (Lehesjoki et al. 1993a,b). When we began this study, we attempted to isolate YAC clones for the region, and with the exception of a small YAC isolated with a probe for PFKL, we were unable to identify clones containing the other known DNA markers in the region. Similar results have been reported by others (Gardiner et al. 1995). For this reason, we used a combination of STS content mapping and walking with bacterial clone libraries to obtain clone coverage of the region. To avoid walking into inappropriate regions of the chromosome or genome, which can occur especially when hybridization probes are used for walking because of low-copy repetitive sequences, we mapped representative clones from each walk to the predicted NotI fragment by PFGE and, in some cases, by radiation hybrid mapping (data not shown). In addition, the agreement in the EcoRI restriction maps of the average of 10 cosmid clones covering most of the contig provides an additional measure of confidence that the clones are localized correctly and that the cosmid clones are very likely not rearranged. Furthermore, the presence of identically sized EcoRI fragments in the regions of the BACs and P1 clones that overlap with the cosmids suggests that these larger insert clones are also a faithful representation of the regions of the genome from which they are derived.

To build the contig, we screened a total of 6432 clones from the chromosome 21-specific cosmid library, representing an estimated sixfold calculated coverage of the chromosome. However, we obtained $\sim 10$-fold redundancy in the clones for most of the region. Thus, for each 50 $\mathrm{kb}$ of DNA, there are 10 overlapping cosmids on average, except for the two regions with single coverage by BAC clones. Because we screened a number of cosmids estimated to be about sixfold coverage of the chromosome, our results indicate that this region of the chromosome is more highly represented in the library than are other parts of chromosome 21.

Although most of the contig is represented as multiple overlapping cosmid clones, there are two segments that are not as well represented in our contig. The region containing BAC $52 \mathrm{C} 10$ and P1 1083A8 has an $\sim 40-\mathrm{kb}$ segment that is covered only by parts of these two clones, and $\sim 35 \mathrm{~kb}$ of the region spanned by BAC $173 \mathrm{~L} 3$ is covered only by that single clone. We used BAC clones $52 \mathrm{C} 10$ and $173 \mathrm{~L} 3$ as probes to screen the LLNL chromosome 21-specific library in an effort to increase clone coverage in those areas but were unable to identify any new cosmids in these screens. These results suggest that there are portions of this region of chromosome 21 that are difficult to clone in cosmids and is consistent with the notion that complete clone coverage of 


\section{CLONE CONIIG OF THE HUMAN EPM1 REGION OF $21,22.3$}

the genome for sequencing and other projects will likely rely on the use of libraries constructed with multiple types of cloning vectors.

Ichikawa et al. (1993) identified five NotI sites in this region, each of which is associated with the linking clones that we used to begin the cosmid isolation. We identified four additional NotI sites not reported by this group, which are those sites that are not digested in genomic DNA from the somatic cell hybrid that Ichikawa et al. (1993) used to construct their NotI map. The clustering of these sites on the map helps to identify positions of potential CpG islands, which may be useful for identifying genes in the region.

A cosmid contig for a portion of the region that we presented in this paper, spanning the $400-\mathrm{kb}$ region from D21S460 (LJ104) to D21S154, was published recently (Lafreniere et al. 1995). These investigators employed a cosmid walking strategy similar to the one we used and determined HindIII and rare-cutter restriction maps of their segment. Because the same cosmid libraries were used in the two studies, it is possible to compare cosmid assignments and orders in the portion present on both maps. We found no inconsistencies in the two maps. In addition to including their region, our contig extends another 350 $\mathrm{kb}$ more proximal, toward the centromere in a region that shows high allelic association with EPM1.

This work provides reagents and mapping information that can be used to identify candidate genes for EPM1. In addition, it may also aid in the isolation of the gene for autoimmune polyglandular disease type 1 (APECED; Aaltonen et al. 1994), which maps between D21S49 and D21S171 DNA markers that lie on either side of our contig. Isolation and identification of the EPM1 gene will allow analysis of the protein product, leading to new insights as to the etiology of EPM1 and may provide insights into other epilepsies as well. Identification of the gene and its mutations will also allow definitive diagnosis of this disease. In addition, our work provides a set of minimal overlapping bacterial clones with detailed restriction mapping data that can be used as templates for determining the nucleotide sequence of this region of chromosome 21.

\section{METHODS}

\section{Libraries}

The arrayed cosmid library LL21NCO" $Q$ " was constructed at the Biomedical Sciences Division, Lawrence Livermore
National Laboratory (Livermore, CA 94550), under the auspices of the National Laboratory Gene Library Project sponsored by the U.S. Department of Energy, and was a generous gift of $P$. de Jong and colleagues (Roswell Memorial Institute, Buffalo, NY). The source of human genomic DNA for this library was obtained from the Wav 17 cell line, a somatic cell hybrid that contains chromosome 21 as the only human component. We screened 6432 clones, which represent about six equivalents of chromosome 21 . The P1 library was constructed at DuPont, Inc. (Shepherd et al. 1994); DNA pools from this library were donated by J.-F. Cheng and E. Rubin (Lawrence Berkeley Laboratories, Berkeley, CA) and correspond to 3.5 equivalents of the genome. DNA pools corresponding to about three genome equivalents from the BAC library were purchased from Research Genetics, Inc. (Huntsville, AL).

\section{Hybridizations}

The cosmid library was replicated onto Hybond $\mathrm{N}+$ (Amersham) membranes, as suggested by the manufacturer, and screened by radiolabeling 30-50 ng of P1 or BAC DNA, or 20-30 ng of cosmid DNA or cosmid restriction fragments, by random priming. Hybridizations were performed in $1 \mathrm{M} \mathrm{NaCl}, 1 \%$ SDS, and $10 \%$ dextran sulfate for $\sim 16 \mathrm{hr}$ at $65^{\circ} \mathrm{C}$, and repetitive sequences were blocked with excess human placental DNA as described previously (Zuo et al. 1993). Filters were washed three times in $0.1 \times \mathrm{SSC}, 0.1 \% \mathrm{SDS}$, at $65^{\circ} \mathrm{C}$ for $20 \mathrm{~min}$.

\section{DNA Preparation}

Cosmid and P1 DNAs were prepared from 5- and 200-ml cultures, respectively, grown in TB with $50 \mu \mathrm{g} / \mathrm{ml}$ of kanamycin. BAC DNAs were prepared from $100-\mathrm{ml}$ cultures grown in TB with $12.5 \mu \mathrm{g} / \mathrm{ml}$ of chloramphenicol. All DNAs were prepared by alkaline lysis.

Linking clones LJ112, LB2T, LJ104, LL23SP, and LB85S were generously donated by $\mathrm{M}$. Ohki (National Cancer Center Research Institute, Tokyo, Japan). Bacteriophage $\lambda$ DNA was prepared by standard plate lysis.

\section{PCR Assays}

STSs were designed for sequences obtained from cosmid end fragments. Ends of cosmid DNAs $(3 \mu \mathrm{g})$ were sequenced by using T7 and T3 primers and Sequenase (U.S. Biochemical) as directed by the manufacturer. Conditions for the amplification of the STSs are available from GenBank. The cosmid fragment bearing the STS was confirmed by hybridization of the radioactively labeled PCR product to an EcoRI digest of overlapping cosmids.

The primer sequences and PCR conditions for STS 2493/2494 were the following: 2493, 5'-GCTTGTCACTCCCACTCTC; 2494, 5'-CCAGCTTCCAGTTGGTGTC; 30 cycles at $94^{\circ} \mathrm{C}$ for $30 \mathrm{sec}, 58.5^{\circ} \mathrm{C}$ for $30 \mathrm{sec}$, and $72^{\circ} \mathrm{C}$ for 30 sec in $10 \mathrm{~mm}$ Tris- $\mathrm{HCl}$ (pH 8.3), $2.5 \mathrm{mM} \mathrm{MgCl}_{2}, 50 \mathrm{mM} \mathrm{KCl}$, and $1 \%$ DMSO. The PCR product is $\sim 100 \mathrm{bp}$. The primer sequences and condtions for STS 2489/2490 were the following: 2489, 5'-GCATCAAGCCATCGGCTTTG; 2490, 5'TCAATGCAGGGAATACTTATAG, 30 cycles at $94^{\circ} \mathrm{C}$ for 30 


\section{STONE EI AL.}

sec, $56^{\circ} \mathrm{C}$ for $30 \mathrm{sec}$, and $72^{\circ} \mathrm{C}$ for $30 \mathrm{sec}$ in $10 \mathrm{~mm}$ Tris- $\mathrm{HCl}$ (pH 8.3), $1.5 \mathrm{mM} \mathrm{MgCl}_{2}, 50 \mathrm{~mm} \mathrm{KCl}$, and $50 \mathrm{~mm}$ ammonium sulfate. The PCR product is $\sim 200 \mathrm{bp}$.

\section{Construction of Restriction Maps}

The EcoRI restriction map was built by determining the sizes of the digested fragments in each cosmid, BAC, and P1 on ethidium-stained $15-\mathrm{cm}$-long $1 \%$ agarose gels, 30 $\mathrm{cm}$-long $0.6 \%$ agarose gels, and $1 \%$ field inversion gels to allow optimal resolution of different sized fragments. The $E c o$ RI restriction fragments were ordered by identifying the internal fragments that overlapped in adjacent clones and determining which fragments were localized to the ends of each clone. The end fragments are different in size in each clone because of the fact that EcoRI was not used to generate the inserts in the libraries. The high level of coverage in the cosmid clones resulted in at least one clone end localizing to each EcoRI fragment throughout almost all of the contig, allowing most of the fragments to be ordered. Although we could order almost all clones and restriction fragments on the basis of these restriction digestion experiments, additional confirmation of overlaps and orders of EcoRI fragments was obtained by hybridizing blots of the agarose gels with published DNA markers, cosmid end fragments, internal fragments, and whole cosmids, as well as by determining the locations of NotI, SacII, and EagI sites in the cosmids with double digests. In addition, many cosmid fragments were used as hybridization probes to Wav 17 DNA digested with NotI and separated on pulsedfield gels.

\section{ACKNOWLEDGMENTS}

We thank the members of the Myers and Cox laboratories, the Stanford Human Genome Center (SHGC), and $O$. Flores for discussions and support, the members of the SHGC for help in STS development, Dr. Pieter de Jong for providing the cosmid library, Drs. Nancy Shepherd and Nat Sternberg for the P1 library, Drs. J.-F. Cheng and Edward Rubin for DNA pools, and Dr. Misao Ohki for providing NotI linking clones. This work was supported by National Institutes of Health (NIH) grants HD-24610 and P50 HG-00206 (to R.M.M. and D.R.C.), postdoctoral grant NIH IF32GM17502 (to J.A.W.), and NIH grant NS31831-02 (to A. d. l. C). The sequence data described in this paper have been submitted to the Genome Data Base under accession nos. 681962 (D21S1988), 655767 (D21S1953), 681566 (D21S1978), 141360 (D21S1259), and 681965 (D21S1991).

The publication costs of this article were defrayed in part by payment of page charges. This article must therefore be hereby marked "advertisement" in accordance with 18 USC section 1734 solely to indicate this fact.

\section{REFERENCES}

Aaltonen, J., P. Bjorses, L. Sandkuijl, J. Perheentupa, and L. Peltonen. 1994. An autosomal locus causing autoimmune disease: Autoimmune polyglandular disease type 1 assigned to chromosome 21 . Nature Genet. 8: $83-87$.
Baxendale, S., M.E. MacDonald, R. Mott, F. Francis, C. Lin, S.F. Kirby, M. James, G. Zehetner, H. Hummerich, J. Valdes, F.S. Collins, L.J. Deaven, J.G. Gusella, H. Lehrach, and G.P. Bates. 1993. A cosmid contig and high resolution restriction map of the 2 megabase region containing the Huntington's disease gene. Nature Genet. 4: $181-186$

de la Chapelle, A. 1993. Disease gene mapping in isolated human populations: The example of Finland. $J$. Med. Genet. 30: 857-865.

Gardiner, K., H. Ichikawa, M. Ohki, D. Patterson, and J.-F. Feng. 1995. Isolation of CDNAs to a region poorly represented in the CEPH chromosome 21 YAC contig: Candidate genes for genetic diseases mapped to $21 \mathrm{q} 22.3$. Genomics 30: 376-379.

Ichikawa H., F. Hosoda, Y. Arai, K. Shimizu, M. Ohira, and M. Ohki. 1993. A Not I restriction map of the entire long arm of human chromosome 21. Nature Genet. 4: $361-366$.

Lafreniere, R.G., P.J. De Jong, and G.A. Rouleau. 1995. A $405-\mathrm{kb}$ cosmid contig and HindIII restriction map of the progressive myoclonus epilepsy type 1 (EPM1) candidate region in 21q22.3. Genomics 29: 288-290.

Lehesjoki, A.-E., M. Koskiniemi, P. Sistonen, J. Miao, J. Hastbacka, R. Norio, and A. de la Chapelle. 1991. Localization of a gene for progressive myoclonus epilepsy to chromosome 21q22. Proc. Natl. Acad. Sci. 88: 3696-3699.

Lehesjoki, A.-E., M. Koskiniemi, M. Pandolfo, A. Antonelli, M. Kyllerman, J. Wahlstrom, A. Nergardh, M. Burmeister, P. Sistonen, R. Norio, and A. de la Chapelle. 1992. Linkage studies in progressive myoclonus epilepsy: Unverricht-Lundborg and Lafora's diseases. Neurology 42: $1545-1550$.

Lehesjoki, A.-E., R. Eldridge, J. Eldridge, B.J. Wilder, and A. de la Chapelle. 1993a. Progressive myoclonus epilepsy of Unverricht-Lundborg type: A clinical and molecular genetic study of a family from the United States with four affected sibs. Neurology 43: 2384-2386.

Lehesjoki, A.-E., M. Koskiniemi, R. Norio, S. Tirrito, P. Sistonen, E. Lander, and A. de la Chapelle. 1993b. Localization of the EPM1 gene for progressive myoclonus epilepsy on chromosome 21: Linkage disequilibrium allows high resolution mapping. Hum. Mol. Genet. 2: 1229-1234.

Murrell, J., J. Trofatter, M. Rutter, S. Cutone, C. Stotler, J. Rutter, K. Long, A. Turner, L. Deaven, A. Buckler, and M.K. McCormick. 1995. A 500-kilobase region containing the tuberous sclerosis locus (TSC1) in a 1.7-megabase YAC and cosmid contig. Genomics 25: $59-65$.

Patil, N., A. Peterson, A. Rothman, P.J. de Jong, R.M. Myers, and D.R. Cox. 1994. A high resolution physical 
CLONE CONIIG OF THE HUMAN EPMI REGION OF 21 1\$22.3

map of $2.5 \mathrm{Mbp}$ of the Down Syndrome region on human chromosome 21. Hum. Mol. Genet. 3: 1811-1817.

Shepherd, N.S., B.D. Pfrogner, J.N. Coulby, S.L.

Ackerman, G. Vaidyanathan, R.H. Sauer, T.C. Balkenhol, and N. Sternberg. 1994. Preparation and screening of an arrayed human genomic library generated with the P1 cloning system. Proc. Natl. Acad. Sci. 91: 2629-2633.

Xie, Y.G., F.Y. Han, M. Peyrard, M.H. Ruttledge, I. Fransson, P. DeJong, J. Collins, I. Dunham, M. Nordenskjold, and J.P. Dumanski. 1993. Cloning of a novel, anonymous gene from a megabase-range YAC and cosmid contig in the neurofibromatosis type $2 /$ meningioma region on human chromosome $22 \mathrm{q} 12$. Hum. Mol. Genet. 2: 1361-1368.

Zuo, J., C. Robbins, S. Baharloo, D. Cox, and R.M. Myers. 1993. Construction of cosmid contigs and high-resolution restriction mapping of the Huntington disease region of human chromosome 4. Hum. Mol. Genet. 2: 889-899.

Received January 10, 1996; accepted in revised form February $15,1996$. 


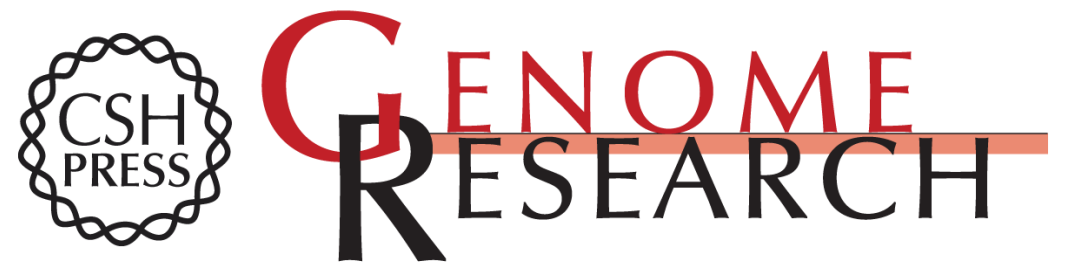

\section{Construction of a 750-kb bacterial clone contig and restriction map in the region of human chromosome 21 containing the progressive myoclonus epilepsy gene.}

N E Stone, J B Fan, V Willour, et al.

Genome Res. 1996 6: 218-225

Access the most recent version at doi:10.1101/gr.6.3.218

References This article cites 15 articles, 5 of which can be accessed free at:

http://genome.cshlp.org/content/6/3/218.full.html\#ref-list-1

\section{License}

Email Alerting

Receive free email alerts when new articles cite this article - sign up in the box at the Service top right corner of the article or click here.

\section{Affordable, Accurate Sequencing.}

To subscribe to Genome Research go to:

https://genome.cshlp.org/subscriptions 